DOI:

\title{
PEMBERDAYAAN MASYARAKAT KAUMAN YOGYAKARTA DALAM PROGRAM PENDIDIKAN KARAKTER DAN BUDI PEKERTI ANAK
}

\author{
Soviyah $^{1}$, Like Diana Nomita $^{2}$, Mita Anggriyani ${ }^{3}$, Norida Jati Prastiwi ${ }^{4}$ \\ ${ }^{1,2,3,4}$ Universitas Ahmad Dahlan, Jalan Kapas, No 9, Semaki Yogyakarta 55166 \\ Email: soviyah@pbi.uad.ac.id
}

\begin{abstract}
ABSTRAK
Masyarakat di Kauman Yogyakarta memiliki potensi sumber daya manusia golongan usia anak anak yang cukup besar. Hal ini karena golongan usia ini akan memegang estafet regenerasi dan memajukan bangsa di masa depan. Dengan potensi yang cukup besar tersebut sayangnya belum diolah dengan efektif. Program KKN Alternatif 61 Universitas Ahmad Dahlan bertujuan untuk memberdayakan dan mengedukasi masyarakat Kauman dalam hal kegiatan pendidikan karakter dan budi pekerti anak agar masyarakat Kauman memiliki wawasan dan pengetahuan bagaimana cara menanamkan karakter dan budi pekerti pada anak sehingga mereka tumbuh menjadi anak yang berkarakter dan berkepribadian positif. Program pemberdayaan melalui KKN ini dilakukan dengan metode pendidikan dan praktik. Hasil dan dampak setelah pelaksanaan program adalah masyarakat terutama anak-anak mengikuti seluruh rangkaian program KKN yang dilaksankaan mahasiswa KKN Alternatif

61 dengan antusias dan semangat. Kegiatan yang dilakukan antara lain pengenalan permainan tradisional, pembacaan cerita rakyat, pelatihan bahasa inggris, dan pelatihan gerak dan lagu. Sementara masyarakat juga memberikan respon yang positif terhadap kegiatan KKN yang dilaksanakan. yang dilaksanakan.
\end{abstract}

Kata kunci : pendidikan karakter, permainan tradisional, kampung kauman

\begin{abstract}
The people in Kauman Yogyakarta have considerable potential human age groups of children. This is because this age group will hold the relay of regeneration and advancing the nation in the future. With such a large potential, unfortunately it has not been processed effectively. Ahmad Dahlan University's 61st Alternative KKN program aims to empower and educate the Kauman community in terms of character education and child character activities so that the people of Kauman have insight and knowledge on how to instill character and character in children so that they grow into children with character and positive personality. This empowerment program through KKN is carried out with education and practice methods. The results and impacts after the implementation of the program were that the community, especially the children, participated in the whole series of Community Service Programs implemented by Alternative 61 KKN students with enthusiasm and enthusiasm. Activities carried out included the introduction of traditional games, reading folklore, English language training, and motion and song training. While the community also gave a positive response to the KKN activities carried out. carried out.
\end{abstract}

Keywords: character education, traditional games, kauman village 


\section{PENDAHULUAN}

Kampung Kauman yang berada di Kelurahan Ngupasan adalah salah satu area yang masuk di wilayah Kecamatan Gondomanan Yogyakarta. Dengan nomor kode kelurahan 34.71.10.0001, Kelurahan Ngupasan memiliki luas wilayah 66,86 Ha dengan batas wilayah sebagai berikut: sebelah utara kelurahan Sosromenduran Kecamatan Gedongtengen, sebelah selatan Kelurahan Prawirodirjan dan Kelurahan Kadipaten, sebelah timur Kelurahan Powokinanti Kecamatan Pakualaman, dan sebelah barat Kelurahan Notoprajan dan Kelurahan Ngampilan. Penetapan batas wilayah Kelurahan Ngupasan berdasarkan Dasar Hukum yaitu Perda DIY Nomor 6 tahun 1981. Kawasan di wilayah Kelurahan Ngupasan terdiri dari berbagai macam yaitu: kawasan perkantoran, kawasan pertokoan dan bisnis, kawasan industri, kawasan wisata, dan kawasan perbatasan antar kecamatan lain. Kawasan perkantoran seluas 9,00 Ha, sementara kawasan pertokoan dan bisnis seluas 12,00 Ha. Kauman juga dikenal sebagai salah satu tujuan wisata utama di Yogyakarta.

Sebagai salah satu tempat tujuan wisata utama di Yogyakarta, Kauman memiliki tantangan sekaligus permasalahan terkait dengan efek dari posisinya sebagai daerah tujuan wisata, khususnya untuk generasi muda Kauman. Anak-anak di Kauman sangat rentan terhadap berbagai pengaruh dan dampak yang timbul karena begitu banyaknya pengunjung yang datang ke kawasan Kampung Kauman. Karena itu anak-anak di Kampung Kauman perlu untuk dipersiapkan sejak dini, diperkuat karakternya agar menjadi generasi muda yang dapat diandalkan, dan salah satu media penanaman karakter dan budi pekerti anak adlah dari rumah dan lingkungannya sebagaimana disebutkan oleh Munir (2010) dan Koesoema (2007).

Berdasarkan pada hasil analisis diatas, pelaksanaan program KKN Alternatif 61 UAD kali ini bertujuan untuk memberdayakan masyarakat dalam hal memberikan edukasi, praktik dan pendampingan dalam hal pendidikan karakter dan budi pekerti pada anak-anak di Kampung Kauman Yogyakarta. Dengan demikian, salah satu program unggulan KKN Alternatif 61 UAD adalah berfokus pada anak-anak melalui kegiatan pengenalan permainan tradisional, pembacaan cerita rakyat, berbagai kegiatan berbasi keagamaan serta pelatihan gerak dan lagu. 


\section{METODE}

Untuk melaksanakan program pemberdayaan masyarakat dalam hal memberikan edukasi, praktik dan pendampingan dalam hal pendidikan karakter dan budi pekerti pada anak-anak di Kampung Kauman Yogyakarta, mahasiswa KKN UAD Alternatif 61 melakukan kegiatan sebagai berikut.

Tabel 1. Matrik Progam Kegiatan KKN UAD Alternatif 61

\begin{tabular}{|c|c|c|c|c|}
\hline No. & Metode & Program & JKEM & $\begin{array}{c}\text { Jumlah } \\
\text { Mahasiswa } \\
\text { KKN yang } \\
\text { Terlibat }\end{array}$ \\
\hline 1. & Praktik & $\begin{array}{l}\text { 1. Pengenalan permainan tradisional } \\
\text { 2. Penyelenggaraan jalan sehat anak } \\
\text { 3. Pelatihan English for Kids }\end{array}$ & $\begin{array}{l}3 \times 100 " \\
3 \times 50 " \\
1 \times 100 " \\
4 \times 100 "\end{array}$ & $\begin{array}{l}3 \\
5 \\
2 \\
9\end{array}$ \\
\hline 2. & $\begin{array}{l}\text { Pendidikan/ } \\
\text { Ceramah }\end{array}$ & $\begin{array}{l}\text { 1. Pembacaan cerita rakyat } \\
\text { 2. Pembinaan fiqih untuk anak } \\
\text { 3. Penyuluhan tentang menghargai dan } \\
\text { menghormati antar umat beragama }\end{array}$ & $\begin{array}{l}1 \times 100 " \\
2 \times 100 " \\
3 \times 100 "\end{array}$ & $\begin{array}{l}2 \\
9 \\
4\end{array}$ \\
\hline 3. & Praktik & $\begin{array}{l}\text { 1. Pelatihan gerak dan lagu } \\
\text { 2. Pelaksanaan kegiatan menggambar } \\
\text { dan mewarnai } \\
\text { 3. Penyelenggaraan kegiatan maghrib } \\
\text { mengaji } \\
\text { 4. Pelatihan musikalisasi anak } \\
\text { 5. Penyelenggaraan aneka perlombaan } \\
\text { olah raga dan seni untuk anak }\end{array}$ & $\begin{array}{l}5 \times 100 " \\
1 \times 100 " \\
5 \times 50 " \\
2 \times 100 " \\
4 \times 50 ”\end{array}$ & $\begin{array}{l}9 \\
9 \\
9 \\
9 \\
9 \\
9\end{array}$ \\
\hline
\end{tabular}

\section{HASIL, PEMBAHASAN, DAN DAMPAK}

\section{A. Deskripsi Wilayah}

Kampung Kauman berada di Kelurahan Ngupasan, Gondomanan Yogyakarta. Kauman merupakan salah satu dari beberapa kampong yang ada di Kelurahan Ngupasan. Nomor kode kelurahan Ngupasan adalah 34.71.10.0001. Secara geografis, Kelurahan Ngupasan memiliki luas wilayah $66,86 \mathrm{Ha}$ dengan batas wilayah sebelah utara yaitu kelurahan Sosromenduran Kecamatan Gedongtengen, batas wilayah sebelah selatan yaitu Kelurahan Prawirodirjan dan Kelurahan Kadipaten, batas wilayah sebelah timur yaitu Kelurahan Powokinanti Kecamatan Pakualaman, dan batas wilayah sebelah barat yaitu Kelurahan Notoprajan dan Kelurahan Ngampilan. Penetapan batas wilayah Kelurahan Ngupasan ini berdasarkan Dasar Hukum Perda DIY Nomor 6 tahun 1981. Itilik dari segi warna tanah, kondisi tanah di daerah kelurahan Ngupasan cenderung berwarna abu-abu dengan tekstur tanah pasiran. Kampung Kauman dan wilayah Kelurahan Ngupasan pada 
umumnya tidak memiliki lahan kritis maupun lahan yang terlantar, dengan tingkat kemiringan tanah mencapai 0,00 derajat. Luas tanah dengan erosi ringan di Kelurahan ini seluas 0,05 Ha dan luas tanah yang tidak ada erosi seluas 67,00 Ha.

Secara demografi, komposisi warga di Kampung Kauman Kelurahan Ngupasan sebagian besar tergolong masyarakat yang berpendidikan. Di seluruh wilayah Kelurahan Ngupasan terdapat 2 TK, 2 SD dan 1 SMA. Jumlah total siswa TK yaitu 112, jumlah siswa SD yaitu 889, dan jumlah siswa SMA 494.

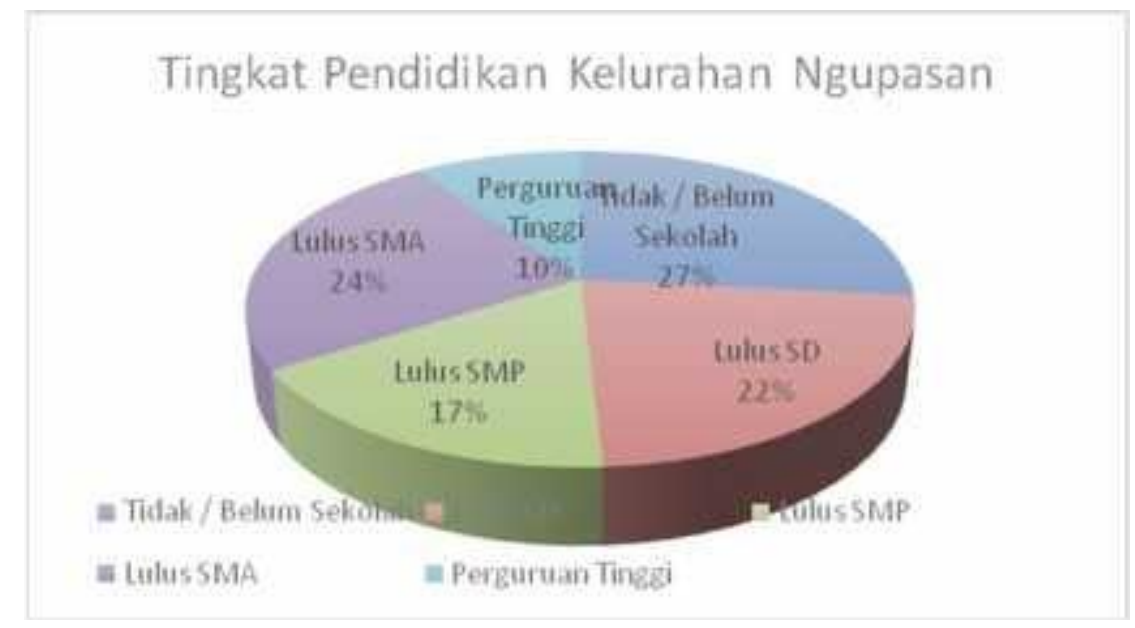

Diagram 1. Tingkat pendidikan penduduk Kelurahan Ngupasan

Dari data ini tampak bahwa golongan usia terbesar adalah kategori usia TK dan SD dengan total mencapai 1000 lebih penduduk, sementara yang usia SMA hanya kurang dari separuhnya. Hal ini cukup menarik. Sebagaimana yang dijelaskan di bagian Pendahuluan sebelumnya, situasi ini bisa merupakan sebuah potensi bagi Kampung Kauman dan Kelurahan Ngupasan pada umumnya. Dengan modal besarnya golongan usia muda ini, dari sudut pandang regenerasi dari warga Kauman dan Ngupasan, dapat dikatakan relatif terjamin.

Sementara itu, ditilik dari aspek kepadatan penduduk, di Kelurahan Ngupasan, termasuk di dalamnya Kampung Kauman, terdapat sekitar 8.551,61 penduduk per KM. Dari keseluruhan jumlah ini, terdiri dari 1859 Kepala Keluarga dan jumlah total penduduk mencapai 5733 orang. Dari keseluruhan jumlah total, dilihat dari jenis kelamin, terdapat 2774 penduduk laki-laki dan 2959 perempuan. Pie chart dibawah ini menunjukkan komposisi antara jumlah penduduk laki-laki dan perempuan yang hampir sama jumlahnya. 


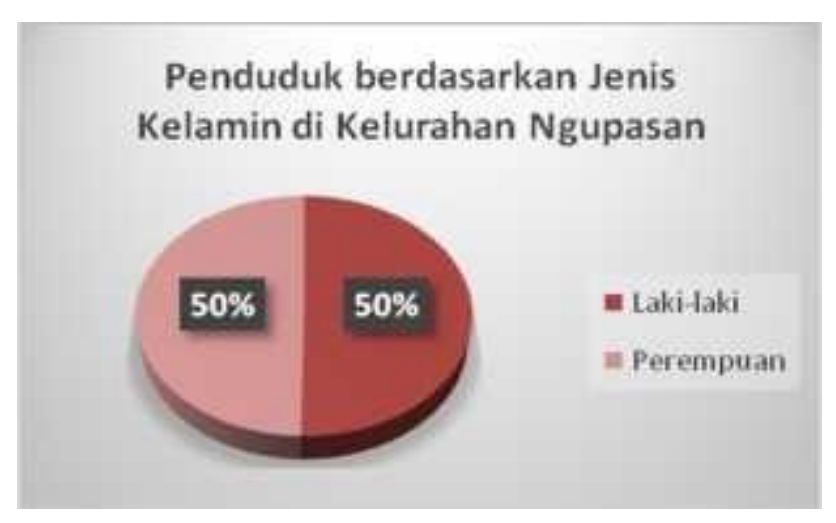

Diagram 2. Komposisi jumlah penduduk berdasarkan jenis kelamin

Dari sisi jenis pekerjaan, masyarakat Kauman yang cukup heterogen memiliki jenis pekerjaan yang heterogen pula. Sebagian besar pekerjaan yang dimiliki oleh warga Kauman adalah industri rumah tangga. Sisanya adalah petani, pedagang, pegawai swasta, PNS, dan sedikit buruh tani.

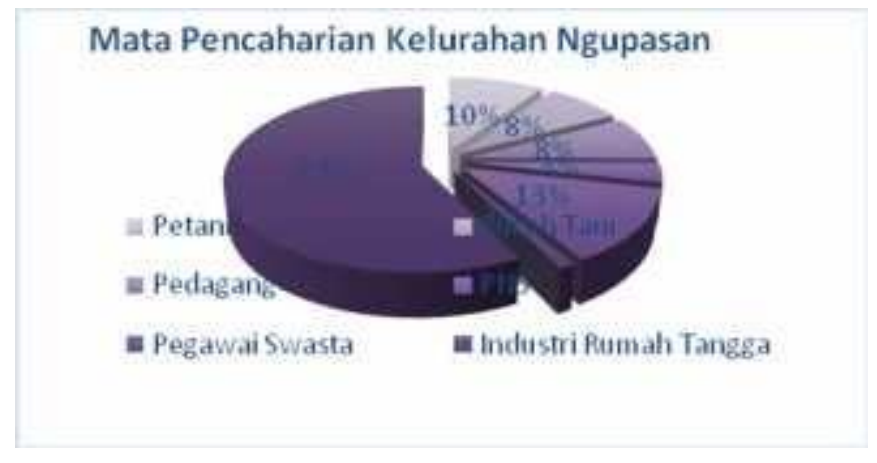

Diagram 3. Mata pencaharian penduduk Keluarahan Ngupasan

Jika ditinjau dari jenis kegiatan yang biasa dilakukan secara bersama-sama, warga Kampung Kauman dan Kelurahan Ngupasan pada umunya memiliki solidaritas dan hubungan antar warga yang cukup bagus. Jal ini tamak dari aktifnya warga dalam melakukan kegiatan di kampong misalnya gotong royong mingguan, pertemuan rutin RT, pertemuan ibu-ibu, pertemuan bapak-bapak dan berbagai kegiatan dan organisasi keagamaan. Bahkan beberapa dari kegiatan tersebut dilakukan dengan dedikasi yang tinggi sebagaimana layaknya sebuah kewajiban dan bukan hanya sekadar kegiatan kampong pada umumnya. Secara umum dapat disimpulkan bahwa secara geografis dan demografis Kampung Kauman dan Kelurahan Ngupasan pada umumnya memiliki potensi yang cukup besar karena wilayahnya berada di daerah yang minim resiko bencana dan warganya sebagian besar berada pada rentang usia muda. Sementara dari 
sisi hubungan antar warga, Kampung Kauman memiliki kulaitas hubungan antar warga yang bagus karena warganya solid, dan aktif.

Tantangannya adalah, bagaimana memberdayakan potensi yang besar ini untuk mengelola warga kelompok usia muda yang cukup besar tadi, agar supaya generasi yang saat ini berusia muda tubuh dan berembang menjadi SDM yang potensial dan berkarakter di masa mendatang.

\section{B. Gambaran pelaksanaan}

Berikut disajikan deskripsi beserta ilustrasi dalam bentuk foto/dokumentasi dari program KKN yang dilakukan mahasiswa.

\section{1) Pengenalan permainan tradisional}

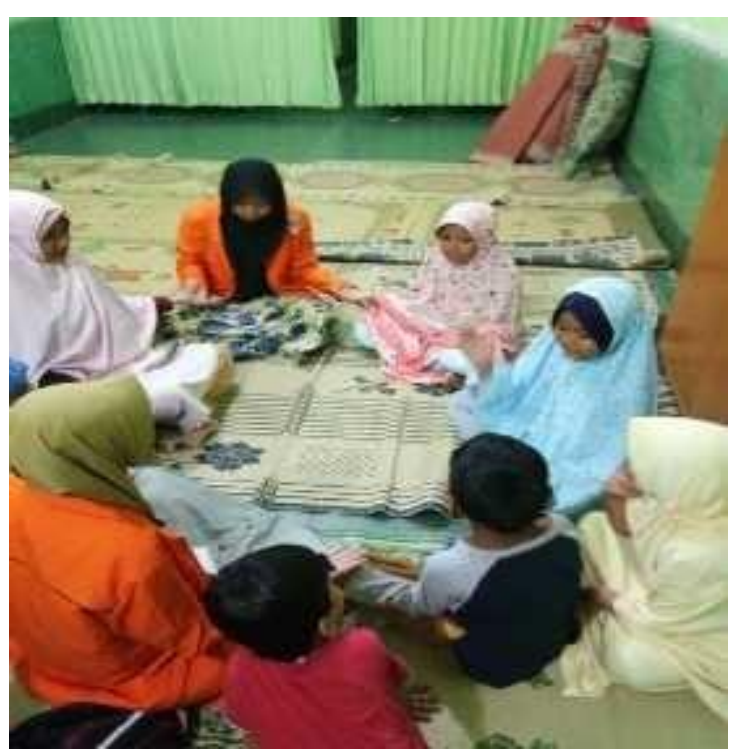

Program pengenalan permainan tradisional bertujuan untuk mengenalkan permainan tradisionla pada anak - anak yang bertujuan untuk menanamkan solidaritas dalam bermain, kompetitif, suportif, memberikan pengetahuan serta pegalaman, meningkatkan tingkat berpikir kritis serta melatih motorik anak. Program ini menyajikan beragam permainan seperti congklak, karet, bola bekel, monopoli.

2) Penyelenggaraan jalan sehat anak

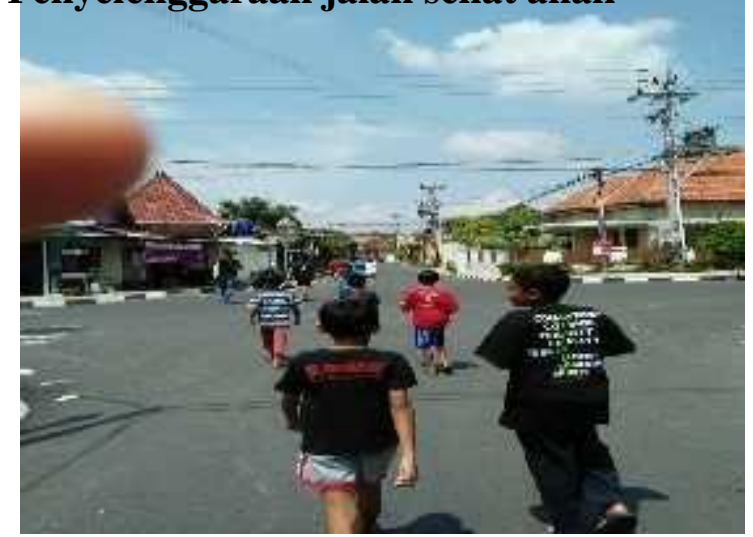

Program kegiatan jalan sehat untuk anak mempunyai tujuan untuk meningkatkan kebersamaan, solidaritas antar anak, serta memupuk nilai-nilai persahabatan yang dilandasi nilai-nila moral. Program ini telah terlaksana dengan rute jalan sehat dari posko KKN hingga ke area Alun-alun Utara Yogyakarta. Selain itu pada program jalan sehat ini juga menyajikan kegiatan atau permainan anak-anak seperti petak umpet dan sepakbola. 
3) Pembacaan cerita rakyat

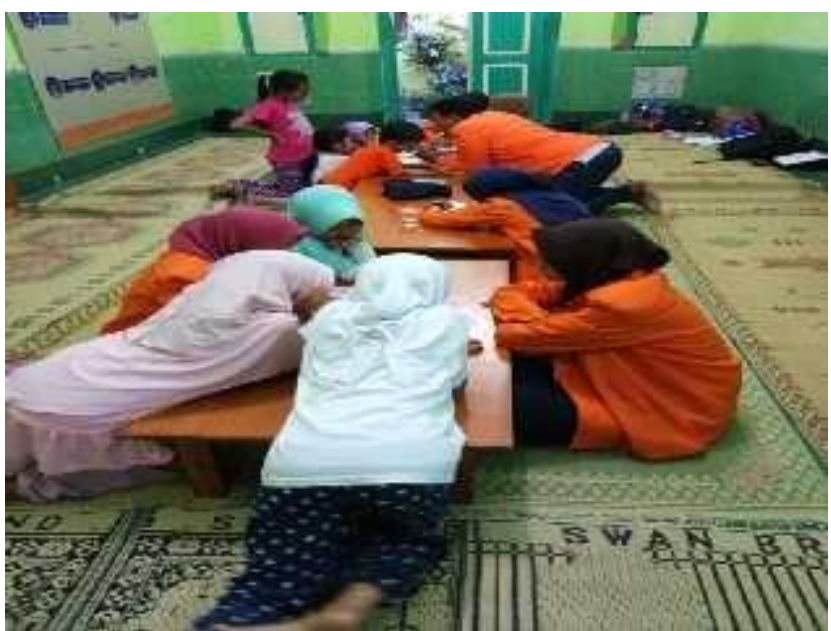

Cerita rakyat merupakan cerita yang tumbuh dan hadir di tengah keragaman bangsa Indonesia beserta keragaman budayanya. Hampir setiap wilayah di Indonesia memiliki cerita rakyat tersendiri dan keyakinan tersendiri dengan cerita tersebut. Program ini bertujuan untuk mengenalkan kebudayaan Indonesia dan menyampaikan pengetahuan serta pesan moral dan budi pekerti luhur kepada anak.

\section{4) Pembinaan fiqih untuk anak}

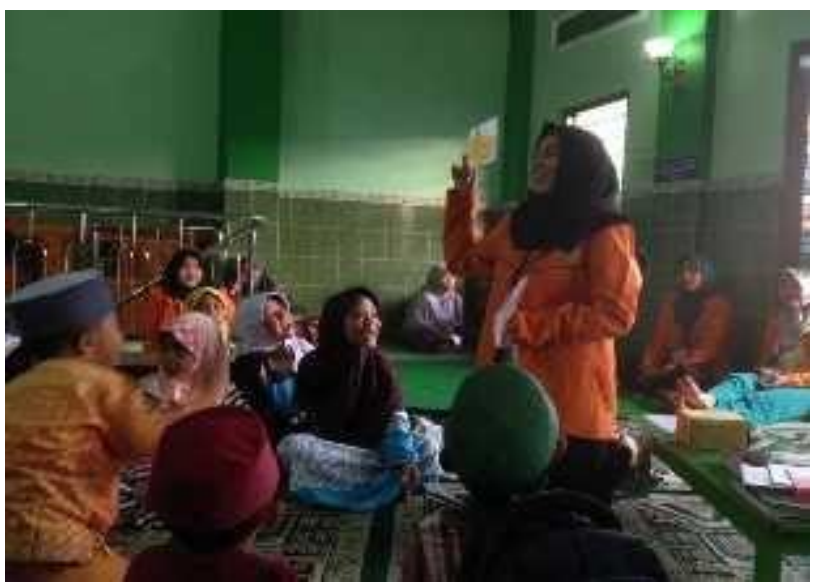

Aspek pendidikan pada anak tidak hanya terbatas pada pendidikan duniawi, melainkan perhatian dan pendidikan yang menyangkut perkara agama, akhlak, dan budi pekerti merupakan suatu hal yang tentunya tak kalah penting. Oleh karena pada program kegiatan ini mencoba mengajak anak untuk mengetahui dan mengenal perihal ilmu dan hukumnya dalam syariat Islam, sehingga pemahaman dalam praktiknya lebih memadai. Dengan metode pemberian materimateri sederhana seperti halnya, bertauhid pada Allah SWT, segala sesuatu yang menjadi keagungan-Nya. Melalui kegiatan ditanamkan karakter dan aqhlak yang baik pada anak. 


\section{5) Gambar pelatihan gerak dan lagu}

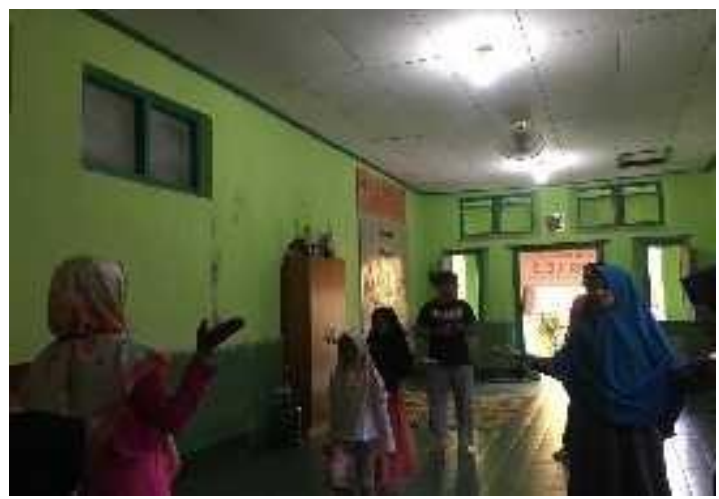

Pelatihan gerak dan lagu bertujuan untuk melatih motoric anak dan memperluas pengetahuan anak tentang budaya terutama tari tradisional. Pelatihan ini meliputi pengenalan beragam tari tradisional dan lagu - lagu tradisional yang mengiringi tari tersebut. Metode yang dilakukan dengan mengajak anak - anak untuk praktik mengaplikasikan gerakan yag dipelajari secara bersama - sama.

\section{6) Pelaksanaan kegiatan menggambar dan mewarnai}

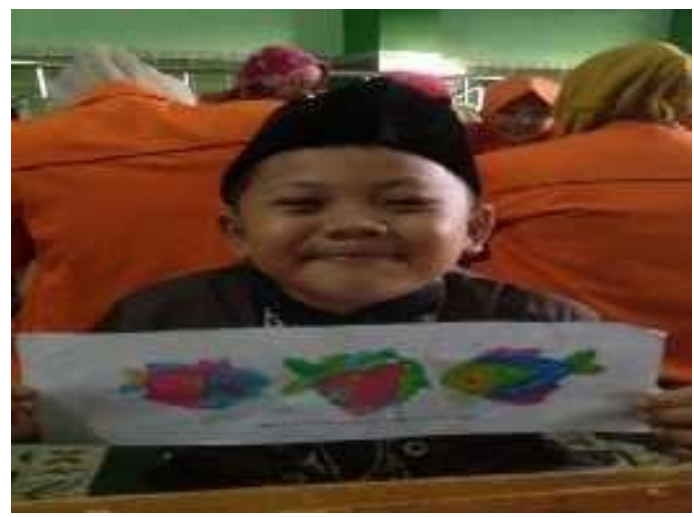

Pada program kegiatan menggambar dan mewarnai ini bertujuan untuk mengembangkan kreativitas anak, komunikasi anak, serta daya tangkap anak dalam penggambaran suatu objek yang ingin dilukiskan pada sebuah gambar. Dengan menyasar segmen anak-anak usia TK hingga SD program ini cukup menarik antusiasme dari anak-anak. Dengan metode yang digunakan adalah dengan menggambar bebas sesuai imajinasi anak-anak dengan pendampingan oleh mahasiswa-mahasiswa KKN. Dengan kegiatan ini melatih kreativitas dan sportifitas anak

\section{7) Penyelenggaraan kegiatan maghrib mengaji}

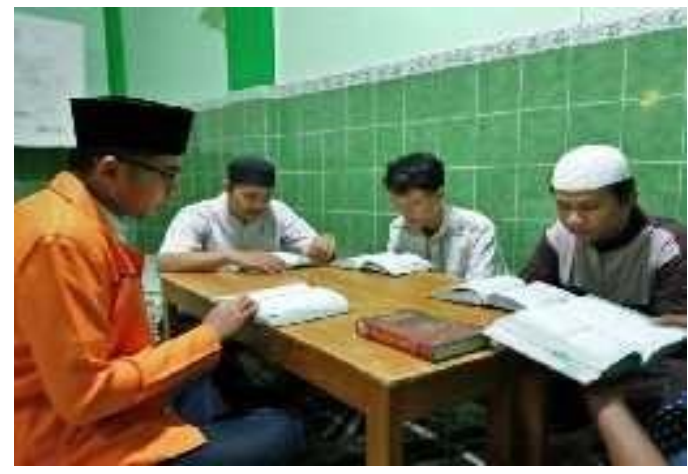

Dalam pelaksanaan program kegiatan maghrib mengaji ini menyasar segmen anak-anak dan remaja dimana bertujuan untuk membiasakan diri agar anak-anak dan remaja senantiasa dekat dengan AlQur'an, meningkatkan kemampuan membaca Al-Qur'an, menumbuh- 
kembangkan karakter \& perilaku sesuai dengan tuntunan dalam Al-Qur'an, memupuk kebersamaan dengan terjalinnya ukhuwah dan tentunya banyak manfaat positif lain yang dapat dipetik. Program ini juga menyajikan diskusi tentang keagamaan. Dengan metode yang digunakan adalah dengan Tadarus bergilir.

\section{8) Penyuluhan sikap menghormati dan menghargai sesama}

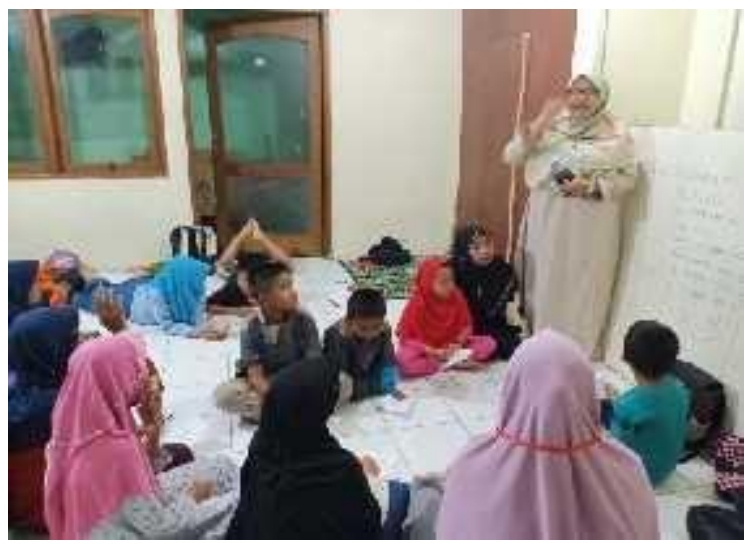

Dalampelaksanaan program kegiatan penyuluhan ini, mengajarkan anak-anak dimana agar mereka membiasakan diri saling menghormati kepada siapa saja termasuk kedua orang tua dan orang yang lebih tua diantara mereka serta saling menghargai sesama teman. Tidak hanya itu, penyuluhan ini guna dalam rangka mengajarkan anak-anak tentang penting nya menghargai orang yang sedang berbicara, dan bagaimana cara bertutur kata yang baik dan benar kepada sesama maupun kepada orang tua agar membentuk anak-anak menjadi pribadi yang lebih sopan dan pandai menghargai serta menghormati.

\section{9) Pelatihan English For Kids}

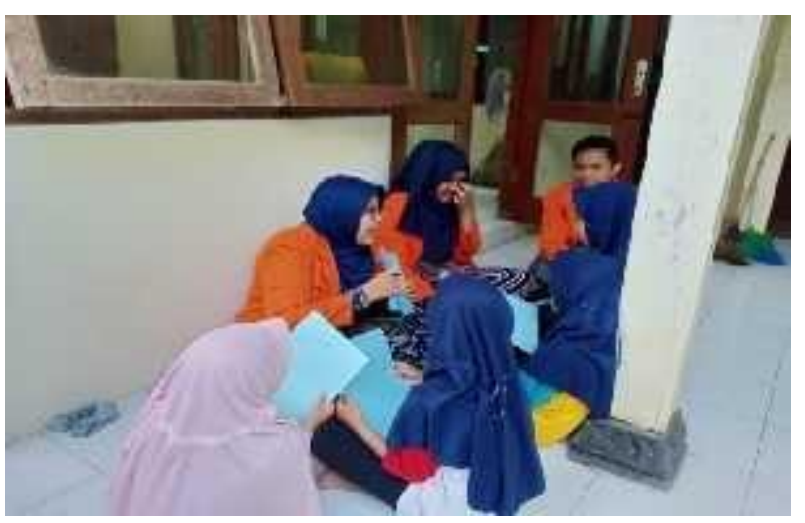

Dalam pelaksanaan program kegiatan pelatihan bahasa inggris untuk anak-anak ini, kami mengajarkan 4 hal. Yakni diantaranya yang pertama, mengenalkan vocabulary yang berkaitan dengan things around us, dimana pada program ini

menyajikan diskusi dengan antar teman dengan mengelilingi lingkungan sekitar. Yang kedua, melaksanakan speaking practice, dimana program ini kita melatih anakanak dalam berbicara menggunakan bahasa inggris. Yang ketiga, membimbing anak carashort story telling, dimana program ini kita juga melatih anak-anak agar bercerita tentang cerita pendek dalam menggunakan bahasa inggris. Yang terakhir, 
mengenalkan English song for children, dimana program ini juga melatih anak-anak dalam bernyanyi menggunakan bahasa inggris.Seluruh program kerja tersebut bertujuan guna mempelajari dan melatih anak dalam berbicara, maupun mendengar dalam bahasa inggris yang baik dan benar.

\section{0) Pelatihan musikali untuk anak-anak}

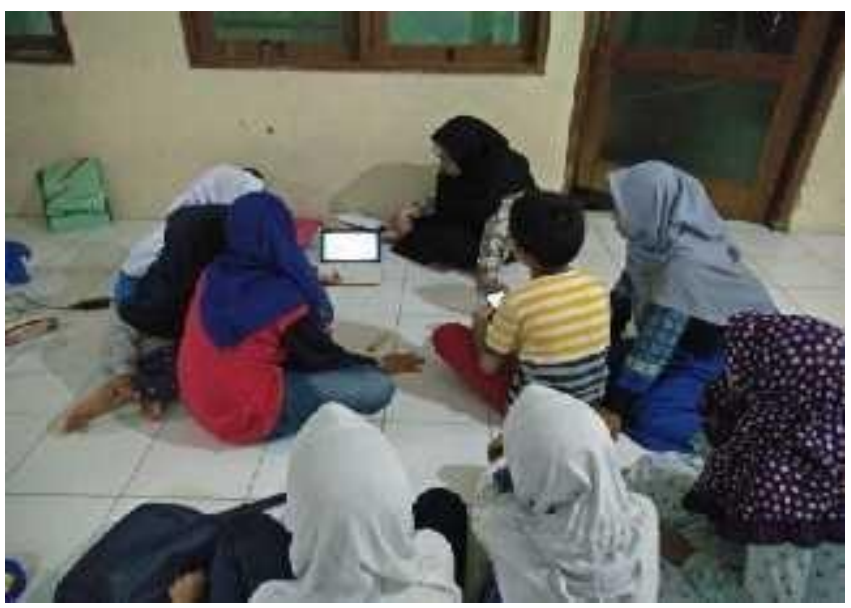

Dalam pelaksanaan program kegiatan pelatihan musikalisasi puisi anak ini dilakukan untuk melatih anak bagaimana membaca puisi yang dilengkapi dengan irama, music dengan kandungan dan isi puisi. Pelatihan ini diadakan untuk melatih kreatifitas, rasa percaya diri, solidaritas,

kekompakan dan rasa tanggungjawab pada anak.

\section{1) Penyelenggaraan lomba untuk anak-anak}

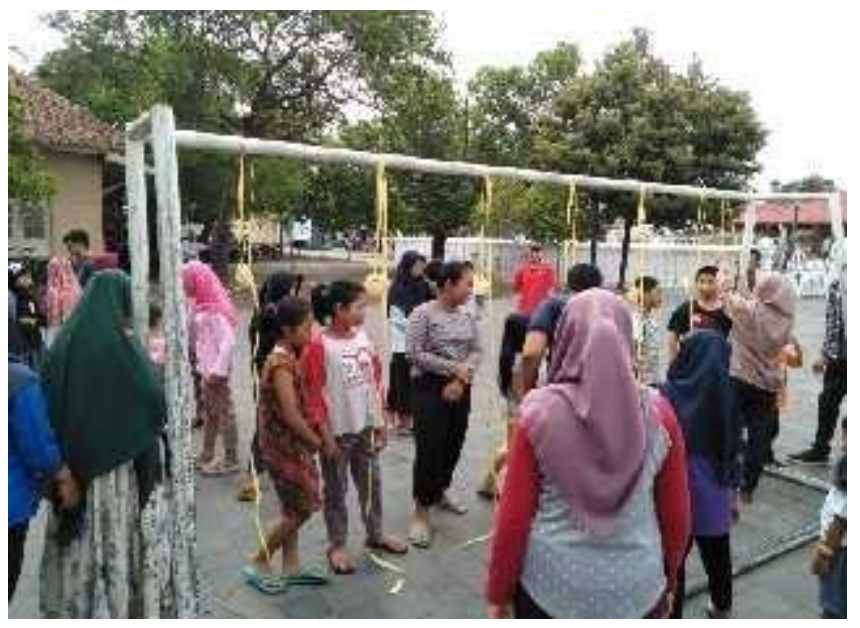

Program kegiatan lomba olah raga dan seni anak ini, terdiri dari beberapa lomba antara lain lomba makan kerupuk, lomba kelereng, lomba joget balon serta lomba estafet air. Diantara lomba tersebut diselenggarakan khusus untuk anak-anak se Kampung Kauman. Perlombaan olah raga dan seni anak ini dimaksudkan untuk menanamkan kreativitas, solidaritas, teamworking, sportifitas dan membangkitkan semangat anak-anak untuk cinta olah raga.

\section{SIMPULAN}

Program - program yang dilakukan KKN UAD bertujuan untuk memberdayakan masyarakat di dalamnya. Sehingga mampu memberikan inspirasi program - program baru 
untuk memberdayakan masyarakat yang potensial di wilayah tersebut sesuai dengan kondisi wilayah. Dari seluruh program dan kegiatan yang dilakukan, dapat dikatakan berhasil karena semua program tersebut telah terlaksana dengan baik. Harapannya adalah semoga program dapat dilaksanakan secara konsisten untuk mengembangkan krakter dan budi pekerti yang luhur pada anak. Dengan modal karakter yang baik anak akan tumbuh berkembang menjadi manusia yang bermanfaat.

\section{DAFTAR PUSTAKA}

Munir, A. (2010). Pendidikan Karakter Anak Sejak dari Rumah. Yogyakarta: Pedagogia.

Koesoema, D. (2007). Pendidikan Karakter: Strategi Mendidik Anak di Zaman Global. Jakarta: Grasindo.

Wahyuningsih, I. dkk. Pemberdayaan Masyarakat Banjar Samiana, Gilimanuk, Bali dalam Program Peduli Lingkungan. Yogyakarta: Universitas Ahmad Dahlan UAD. 
